\section{ON SOME OF THE PRINCIPAL EVENTS IN THE CLINICAL HISTORY OF ASTHMA.}

By II YDE SALTER, M.D., F.R.S., Fellow of the Royal College of Physicians, and Assistant-Physician to Charing Cross Hospital.

VIII.-The Asthatitic Physique; its Distinctivexess; its Charactiristic Gait, Physiognomi, and Configuration; Rationale of the Asthatatic Spinal Curvature; Pecuilar Chlst of young Asthmatics.

Astrina is a disease that stamps on the body its own indelible marks. So characteristic and unmistakeable is the physique of asthma, so plainly, so legibly does the asthmatic bear about with him the impress of his disease, that any one who has once observed it will never fail to recognise it, and would be safe in basing a diagnosis on its unaided testimony. In con. firmation of this, I may mention a circumstance or two that have occurred to myself.

I frequently meet in the streets of this city a distinguished savant, who is a great sufferer from asthma, and if I were to meet him at Pekin I should lnow him to be an asthmatic. The first time I saw him, I was walking behind him, but immediately recognised the characteristic configuration. So certain did I feel of it, and so curious was $I$ to see if I could derive from his face any confirmation of my impression, that I overtook him, and as I passcd, saw at once who he was, from his resemblance to a photograph $\mathrm{I}$ had seen of him; and then I remembered what I had heard about his malady. This previous knowledge, however, could have had nothing to do with my impression, as at first I had no idea who he was, in fact had never seen him before.

On another occasion, I was going down to Brixton in an omnibus, and sitting next to me was a gentleman, whose figure and appearance very mach struck me. He looked well in the face, was breathing without the slightest difficulty, and was engaged in animated conversation with his next neighbour. But 1 felt sure he was an asthmatic; he was exceedingly thin his shoulders very high, and his back so rounded, that though quite a tall man, he sat lower, a good deal, than I did. He left the omnibus before me, and in walking his stooping gait and rounded back were still more conspicuous. When I left the omnibus, I asked the conductor "If he knew that tall, thin, stooping gentleman" that got out at such and such a place. "Oh ves, he said," it is Mr. - of - . " "Do you know," I asked, "if he is sulject to a complaint in his chest, that gives him fits of difficult breathing?" "Oh! yes," he replied, " and has been for a long time-for years; sometimes he can hardly walk to the omnibus."

Here then are two cases in which I recognised the presence of asthma, merely by the changes in the physiognomy and configuration which it produces. I have dore the same thing in several other instances. I often say to myself as I pass an individual in the street with the characteristic configuration"You are an astlimatic."

What then is this unmistakeable impress of asthma? How is it to be described? In what peculiarities does it consist? Partly those of the figure, nartly those of the face. In configuration, the asthmatic is round-backed, high-shonldered, and stooping; but while the body is bent forwaris the head is thrown back, and buried, as it were, between the elevated shoulders. There is no movement or pliancy in the body, but the chest is fixed and rigid, like a box, and from it the arms depend, hanging motionless, or swinging like two pumphandles, rather thrown back, and bent at the elbows. In walking, the legs seem the only part of the body that moves. From the roundness of the back, the asthmatic, for his height, always sits low. Those who have suffered from asthma long, are almost invariably thin, often to a degree amounting to emaciation; their limbs are attenuated and bony, every rib can be counted, and their clothes hang loosely on them. From the entire absence of subcutaneous fat, the sunerficial veins are very conspicuous; though it is possible that venous obstruction, from impeded circulation through the lungs, may have something to do with their prominence,- that it may be, in fact, slight general varix. The prominence and tortuousness of the veins is sometimes remarkable, especially in old asthmatics. The hands of an asthmatic are very charac. teristic; they are cold, blue, thin, and veiny. This blueness and coldness of the extremities is partly due, no doubt, to the feebleness of the circulation in them, but in part, especially if there is some permanent dyspnœa, or the patient is at the time suffering from an attack, to imperfect decarbonisation of the blood.

But this blueness of surface is not confined to the extremities; the complexion of the asthmatic is often distinctly cyanotica slight but perceptible duskiness. Where, however, there is no dispncea between the attacks, and the intervals are long, especially in young subjects, I do not think the complexion is perceptibly affected.

The face has generally rather an anxious expression, and often bears an aspect of age greater than the real age of the patient; even if not dusky, it is always pale, and like the rest of the body, is thin-the cheeks are hollow, and the lines of the face are deeply marked. The mouth is generally open, and the jaw rather hanging. There is a peculiarity about the eyes to which I would call particular attention, to which I often have directed attention among the patients at the hospital, and on the strength of which alone I have frequently diagnosed asthma; they are turgid, watery, and prominent. I believe this to depend, like the enlargement of the superficial veins, upon venous obstruction; the turgidity is that of the veins of the conjunctiva; the wateriness is due to an unusual amount of mucus and tears, which the engorged mucous membrane and lacrymal gland pour out, while the prominence is due to the turgidity of the veins of the orbit. Wherever I find this ap pearance of the eyes in connexion with chronic asthma, I look out for dilated right heart.

The asthmatic's voice is often very peculiar; it is feeble, and slightly hoarse and rough; he speals as a healthy person would speak, if he were to expire as long as he could and then begin to speak, - as if he were making use of the last breath in his lungs; and it is indeed to the small respiratory resource that he has for speech that this feebleness and roughness of the voice is due. His sentences are short, and frequently in terrupted by a single dry cough.

Many of the external characteristics of asthma that I have enumerated, such as the gait, the dusky complexion, the eyes, the voice, will be seen at once to be those rather of chronic dyspnœa than of astluma, and I would so far qualify their value as diagnostic signs. Indeed, their value is rather generic than specific. In the purest cases of spasmodic asthma, in which there is no trace of dyspnœa in the intervals, they are the least marked, and are the most conspicuous in those which are complicated with some chronic bronchitis or bronchial congestion, so that I look upon their absence as a good sign, as a sion that the lungs are sound and unscathed; and it is because asthma seldom exists long without producing such changes as permanently embarrass the breathing, that these changes in the physiognomy and configuration come to be signs of asthma they are just as much a part of its clinical history as those internal changes in the lungs and heart, of which they are the sure sign and accompaniment. I have, however, seen the asthmatic physique very strongly marked in some cases where the lungs were orranically sound; but these were always cases where the paroxsyms were very long, lasting for days or weeks, so that the efficient cause was in continued operation for long time; or else they were cases in which the asthma had been very severe in childhood, when the figure was forming, so that it got set in the asthmatic shape, and, although the disease afterwards quite disappeared, the tigure never recovered itself Such cases carry a certain highness of shoulders and roundness of back with them to the end of their days.

The degree of deformity of the back is, in some cases, truly remarkable; and (although I have not examined any of the spines of these cases after death) such as I cannot but think must involve some anatomical change in the bones or intervertebral discs. The curvature is always direct anteroposterior, never lateral, and involves the middle or lower dorsal vertebræ. In one case, I have seen the angle made by the curvature almost as considerable as an angle of a hundred degrees. Now, it is certain that such a change in direction as this, almost a right angle, effected within the length of a few vertebræ, could only be produced by a great shortening of the anterior aspect of the column, involving a vertical shortenin of the anterior part of its separate elements-vertebre, or intervertebral discs, or both-converting the bodies of the 
vertebræ, or the discs of fibro-cartilage between them, into wedges, as shown in the accompanying diagram.

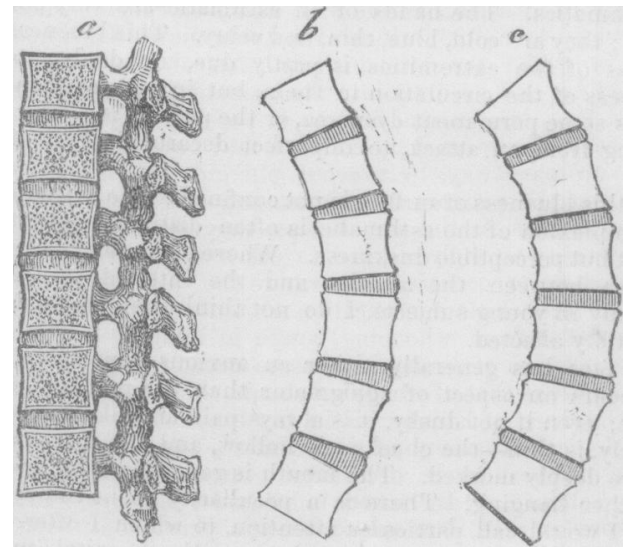

Fig. 1 .

a. Vertical Section of the Spinal Column

$b$ and $c$. Anterior Spinal Curvature produced by absorption from pressure in the anterior parts, in the one, of the intervertebral dises, in the other, of the bodies of the vertebris.

Now, the agency by which a disease affecting the air-passages produces this curvature of the spinal column was not very clear to me, and it was long before I arrived at what I believe to be its true explanation. It certainly was not a change of form having for its object the enlargement of the thoracic cavity, like the barrel-chest of emphysema; it was manifest that such a deformity must materially prejudice the size, the shape, and the movements of the thorax. It was equally certain that there was no spinal disease; that the curvature was the result of repeated attacks of asthma; that it was the permanent retention and constant aggravation of the asthmatic stoop which always exists during the paroxysms. 13ut, beyond this, its nature and causation did not appear intelligible. At length $I$ was guided to what appears to me to be its true rationale by the following considerations.

1. Pressure produces absorption of the part pressed on; e.g., the absorption of the sternum and ribs in aneurism.

2 . In stooping-i.e., in forward curvature-there is vertical pressure along the anterior face of the spinal column; i.e. its elements exercise vertical pressure upon one another in their anterior portions.

3. The unsupported spine tends to fall forward-i.e., to anterior curvature; the whole array of the muscles of the back are erectors of it.

4. When the muscles of extraordinary respiration are engaged in extraordinary respiratory efforts, they cease to play their ordinary rôle: e.g., the omo-hyoid muscle is ordinarily a depressor of the hyoid bone, but in asthma it is an elevator of the scapula, and powerless to depress the hyoid bone: the sterno-mastoid is ordinarily a rotator and anterior flexor of the head; in asthma, it is an elevator of the sternum, and power. less to move the head.

I infer, therefore, that the muscles of the back, being engrossed during the asthmatic paroxysm with their violent respiratory labour, cease to act as erectors of the spine. The back is, therefore, unsupported, and obeys its natural tendency to fall forward. This, I am sure, is the true explanation of the asthmatic stoop; and we see, consistently with this view, that any effort to straighten the back is immediately attended with additional distress, because the muscles are temporarily withdrawn from their respiratory exertions; and that the stooping is always in proportion to the dyspnca-that is, in proportion to the degree in which the muscles of the back are engrossed by the breathing. The back being, therefore, left thus to itself, and falling thus forward, the anterior parts of the bodies of the vertebra and intervertebral discs are pressed together; and if the asthmatic state is continued long, and occurs frequently, this pressure is so protracted that it produces absorption of this part of the bodies of the vertebræ, or the intervertebral fibro-cartilages, or both; they become wedgeshaped, and the temporary stoop becomes a permanent curvature.

Now, I admit that I have never examined, post mortem, the spine in cases of this asthmatic deformity; and I merely offer this hypothesis as a reasonable explanation. In cases in which I have seen it, there has not existed the slightest ground for believing that there was any spinal disease. In the case of William Burr, before the asthma came on, the back was straight, the patient tall; but as the asthma became worse and the attacks longer and more frequent, the stoop, which he always had during the attacks, went off less and less in the in. tervals, and gradually became more and more considerable, till it settled into the permanent deformity which now exists, and which, though his legs are long, has made him quite a short man. No pain is experienced in the back in these cases (except an aching of the dorsal muscles during the asthma, from their violent respiratory exertion). Moreover, the curvature is never confined to a single vertebra, or to two or three, and is never angular; it is rounded and gradual, and involves a considerable portion of the back. In such an absence of all evidence of spinal disease, and with an amount of curvature in some cases making some change of form in the elements of the spine a physical necessity, I do not see what explanation can be offered other than that I have given. If correct, it is certainly interesting; it has the interest of all facts which elucidate a modus operandi, and furnish the connecting links between associated, but apparently diverse phenomena.

When my mind was engaged in thinking on this subject, a case of another nature occurred to me which confirmed my ideas, and seemed to show that mere loss of power on the part of the muscles of the back was adequate to the production of anterior spinal curvature. A man in the prime of life, with an erect figure, who had never had anything the matter with his spine in any way, was seized with severe rheumatism in the muscles of the back, and the pain was so aggravated and rendered so intense by attempting to stand upright, that the muscles refused to perform their office ; the unsupported spine bent forward as far as its elasticity would permit, and the back became round and the gait stooping, like that of an old man. This went on for some months, without any decided curvature appearing; at length, distinct and gradually increasing curvature manifested itself, involving the seventh and eighth dorsal vertebræ, and to such an extent as to show that their bodies. must have undergone some change of shape. The patient recovered from his rheumatism, regained the power of supporting his back, and the curvature was arrested; but it has never disappeared.

If, then, loss of power of the spinal muscles, paralysed by rheumatic pain, is adequate to the production of organic curvature in the way that I have supposed, why should not their paralysis, as erectors of the spine, from their being engrossed in their respiratory action, be attended with the same result?

In young asthmatics who have suffered from their disease in infancy, I have observed a configuration of chest which I have seen, to a certain extent, in cachectic rickety children who have not suffered from asthma, but which I am not sure I have ever seen in children who have not suffered from any chest-affection. I am not sure, therefore, what share in the production of the deformity ought to be assigned to the asthma, or what to the deficient strength of the bony parietes of the chest; or whether imperfect ossification and chestmischief are both necessary for its production. What inclines me to think that the latter cause is the chief one (or, at least an essertial one), is, that the deformity is just such as would be produced where there was an impediment to inspiration, and where violent but ineffectual inspiratory efforts were made by weak parietes-just such, in fact, as one sees in the inspiration of atelectasis or laryngitis.

In these cases, the upper part of the chest-above the fourth or fifth rib-is naturally shaped; but below that level, on each side of the sternum and along the margin of the false ribs, corresponding to the cartilages of the seventh, eighth, ninth, and tenth, the surface, instead of being convex and fuil, is ex cavated in two hollows. These hollows are bounded internally by the lower part of the sternum, which stands forward between them in a ridge, and externally, by the extremities of the ossified portions of the rib, which form a ridge on the outside. (Fig 2.) The situation of this flattening in the thoracic parietes-its coincidence with the cartilages of the ribs-suggests the way in which it is produced, and explains how asthma might cause it. I take the method of its production to be this :-When there is any impediment to the ingress of air into the lungsfrom narrowed bronchial tubes, as in asthma, or any other way - the air cannot rush in so fust as the thoracic parietes are expanded, a partial racuum is therefore formed in the chest, and the pressure of the air within it no longer balances that of the air without. This unbalanced external atmospheric pressure 
presses on the whole of the thoracic parietes equally, and drives in the most yielding; in other words, the bony ribs, raised against it by the respiratory muscles, are able to resist it, but the soft cartilaginous portions are not. It must be remembered, too, that the diaphragm' is attached along the margins of all the

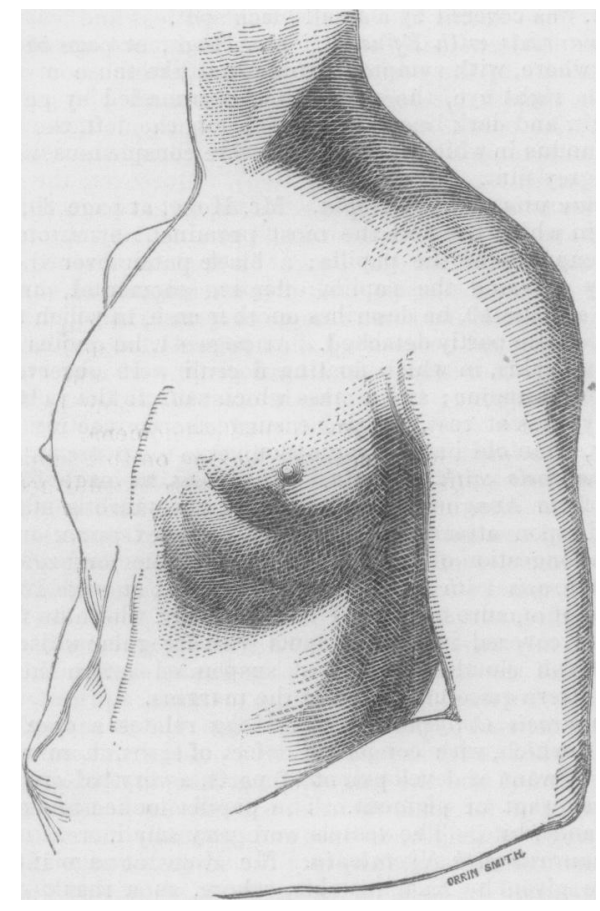

Fig. 2.

Pigeon-chest in Asthma dating from infancy.

ribs below the fifth; its strong contractions during the asthmatic paroxysms would tend therefore to draw them in, and being less opposed by their yielding cartilaginous portions, would concur in the production of this change of shape. This condition would, of course, at first only last as long as the paroxysm; but if the attacks were frequent and severe at a time when the cartilaginous portion of the ribs was considerable and the figure forming, one can easily understand how the deformity would become permanent, and how asthma would in this way produce such a change in the form of the chest as I have been describing. Still more easily could we explain its production by asthma, if we suppose asthma capable of giving rise to pul. monary collapse, in the way I have suggested.

But the actual event to which I think this form of chest directly points - the particular morbid change that it immediately implies-is pulmonary collapse. One cannot but be struck, on looking at such chests, with their exact resemblance (except in the absence of what one may call the diaphragmatic stricture - the drawing in of the attachment of the diaphragm at each inspiration, as if a ligature were put round the body) to the shape of the chest in the inspiration of infants suffering from bronchial plugging, or its established result, atelectasis, or croup, or laryngitis, or any affection that, preventing the ingress of air and the expansion of the lung, refuses to ullow the parietes to follow the movements of the inspiratory muscles.* Pulmonary collapse would certainly be a more potent cause of this deformity than unaided asthma, because it is a more permanent condition and involves a more complete inexpansibility of lung, and therefore would more effectually resist the inspiration-movement of the softer parts of the parietes.

In as far, then, as this heteromorphism points to atelectasis, its occurrence in cases of asthma tends to confirm what I have already said of the tendency and sufficiency of that disease to produce this condition of lung. But remembering that it is

* I have seen it strongly marked in the inspiration of laryugitis, even in ailults. only in cases that have become asthmatic young that this state of chest is well marked, and remembering how commonly asthma dates in the young from catarrhal bronchitis, from the bronchitis of measles, or from what has been called "whooping cough with bronchitis", which is nothing more than whooping cough in which the bronchitic portion of the malady has extended far and severely into the bronchial tree-remembering this, I say, one cannot but see it possible that, at least in many cases, the pulmonary collapse may have been produced in the ordinary way, by mucous plugging of the bronchial tubes from the primary bronchitis, and not from the consequential asthma, in the way I have suggested. I have seen this deformity strongly marked in cases where ordinary bronchitis had never occurred, and where the patient was entirely free from bronchitic complication or tendency; but then the asthma dated from whooping cough in infancy-and, in my opinion, no form of bronchitis has so great tendency to generate collapse as that of whooping cough.

Dr. Gairdner, of Edinburgh, in his excellent papers on the "Pathological Anatomy of Bronchitis", alludes to this de formity of chest as an occasional permanent result of pulmonary collapse. "In rickety individuals," he says, " it is not only more marked, but apt to become permanent, especially when such subjects are affected with any considerable or persistent bronchitic affection. In such cases, the reversed movement of the ribs is stereotyped, as it were, in the form of chest, called pigeon.chest, in which the sternum is protruded, particularly below, and the whole lateral region, including also the lower costal cartilages in front, flattened, or even at some points rendered irregularly concave."

One result of this collapse of the cartilages of the ribs is that they do not stand out from the sternum as they should; but decline from it at too acute an angle, narrowing and elongating the scrobiculus cordis.

Fig 2, a very good example of this configuration, is taken from a photograph of an asthmatic who suffered from his disease from the age of three months. The condition has existed from his earliest recollection, and during his childhood was much more considerable, for since he has grown up his disease has left him, and the shape of his chest has much improved.

\section{ILLUSTRATIONS OF THE USE OF THE OPHTHALMOSCOPE.}

By Wilinam $\mathrm{M}_{\triangle \mathrm{R} T I N}$, F.R.C.S., late Professor of Ophthalmic Surgery in the Calcutta Medical College.

\section{[Continued from page 624.]}

\section{Retrisa.}

THE affections called amaurosis and amblyopia will be noted together. Although these are not accurate scientific terms, they do well enough, in the present state of our knowledge, to indicate the physical symptoms and the derangement of vision attendant upon a well known condition, involving local and constitutional changes, the causes of which are, in the very large majority of cases, not ascertainable. It is only now that, since the introduction of examination by the ophthalmoscope, we are beginning to discover the local conditions upon which the derangements depend. In time, we shall be able to know something of the efficient and proximate causes of these conditions. We may even at present classify, in most instances, amaurosis as being organic or incurable, or only functional or curable; as being caused by disease of the brain or of the optic nerve, retina, or choroid, principally; and this we do chiefly by our observation of the state of the fundus, and of the condition of the optic papilla and its vicinity. If the disease, however, lie somewhere between the optic nerve and the brain, it will not be discoverable by the ophthalmoscope; and if we find changes in the optic nerve, we may not know whether this is the essential disease, or whether it may be only symptomatic of diseased brain. It may be observed, that where we find the papilla compressed and atrophied, we have one indication for concluding that the efficient cause of the disease is external to the globe. The great practical utility of this improved means of diagnosis is, that whereas formerly, in a very large number of cases of amaurosis, various heroic measures were resorted to, in the way both of depletion and stimulation, where we find a state of organic amaurosis, or have seen strong reason to suspect that such a state exists, we shall avoid any such heroic remedies. On the other hand, whereas in many cases of amaurosis, they were set down from the first as incurable, and 